AGRO-INDUSTRI

Vol. 3 No.1 ; Juni 2016

\title{
OPTIMASI PEMBUATAN KURTO (KURMA TOMAT)
}

\author{
"MUHAMMAD RUSTAM EFFENDI ${ }^{1}$, NURYATI ${ }^{1}$, JAKA DARMA JAYA ${ }^{1}$ \\ ${ }^{1}$ Jurusan Teknologi Industri Pertanian, Politeknik Negeri Tanah Laut, Jl. A. Yani, Km. 6, Ds. \\ Panggung, kec. Pelaihari, kab Tanah Laut, Kalimantan Selatan
}

Naskah diterima : 22 April 2016 ; Naskah disetujui : 30 Mei 2016

\begin{abstract}
ABSTRAK
Tomat (Solanum lycopersicum) merupakan salah satu sayuran yang sangat terkenal di Indonesia. Namun pemanfaatannya hanya sebatas sebagai lalapan dan bahan tambahan dalam masakan. Tomat juga bisa untuk diolah berbagai macam produk olahan misalnya, manisan, selai, sirup, saos, dll. Tujuan penelitian ini untuk optimasi pembuatan kurto (kurma tomat) dan untuk mendapatkan kurto terbaik dengan analisis kadar air dan vitamin C. Optimasi pembuatan kurto menggunakan gula pasir dan gula merah. Parameter pengujian kurto meliputi kadar air, vitamin $C$, dan uji organoleptik. Uji organoleptik meliputi warna, aroma, rasa, dan tekstur. Analisis data yang digunakan uji Anova (uji F) yang dilanjutkan dengan uji DMRT (Duncan Multiple Range Test). Hasil yang diperoleh menunjukkan perlakuan terbaik adalah optimasi penambahan gula pasir dan gula merah adalah penambahan gula merah $30 \mathrm{~g}+5 \mathrm{~g}$ gula pasir.
\end{abstract}

Kata Kunci : Tomat, Manisan, Kurto

\section{PENDAHULUAN}

Indonesia merupakan negara yang beriklim tropis sehingga membuat beranekaragam tanaman/sayur-sayuran dapat tumbuh dengan subur di Indonesia. Salah satunya sayuran yang hampir bisa ditemui di seluruh wilayah Indonesia yaitu tomat.

Tomat (Solanum lycopersicum) merupakan salah satu tanaman yang sangat dikenal oleh masyarakat Indonesia. Pemanfaataan tomat hanya sebatas sebagai lalapan dan bahan tambahan dalam masakan. Daerah Kabupaten Tanah Laut sayuran tomat sangat banyak ditemukan, pada tahun 2009 produksi tomat mencapai 4,228 ton (Badan Pusat Statistik Kabupaten Tanah Laut, 2010). Tomat juga bisa untuk diolah berbagai macam produk olahan misalnya, manisan.

Manisan adalah salah satu bentuk makanan olahan yang banyak disukai oleh masyarakat. Rasanya yang manis bercampur dengan rasa khas buah, sangat cocok untuk dinikmati diberbagai kesempatan (Hasanah, 2010). Ada juga manisan kering, manisan kering adalah produk olahan yang berasal dari buah-buahan dimana pemasakannya dengan menggunakan gula kemudian dikeringkan (Hasanah, 2010)

Berdasarkan latar belakang diatas maka pembuatan jurnal ini memanfaatkan tomat untuk diolah menjadi suatu produk yaitu kurto (kurma tomat) yang bernilai ekonomis cukup tinggi dan juga karena bahan bakunya mudah didapat serta melimpah.

*Korespondensi:

Telp. : 08122581589

Email : nuryati77@yahoo.com 


\section{METODE PENELITIAN}

\section{Waktu dan Pelaksanaan}

Pembuatan kurma tomat (kurto) ini dilaksanakan pada bulan Februari - Juli 2016 yang bertempat di Jalan Sawahan RT.25 RW.06, Kec. Pelaihari, Kab. Tanah Laut, sedangkan untuk uji vitamin C dan kadar air dilakukan di Laboratorium Kimia Teknologi Industri Pertanian Politeknik Negeri Tanah Laut dan uji organoleptik dilakukan di Jl.A. Yani RT. 02 RW. 01 Kec. Pelaihari, Kab. Tanah Laut, Prov. Kalimantan Selatan.

\section{Alat dan Bahan}

Alat yang digunakan yaitu Pisau, baskom plastik, sendok makan, timbangan, gelas beaker, kompor gas, panci, nyiru bambu, kain kasa, dan kertas. Sedangkan bahan yang digunakan yaitu tomat merah segar, gula pasir, gula merah, kapur sirih, vanili bubuk, air bersih untuk merendam, dan air untuk merebus.

\section{HASIL DAN PEMBAHASAN}

\section{Formulasi Penentuan Kurto}

Pembuatan Kurto (Kurma Tomat) dilakukan dengan delapan perlakuan yaitu ; K1 $=100 \mathrm{~g}$ Tomat: Gula putih $100 \mathrm{~g}, \mathrm{~K} 2=100 \mathrm{~g}$ Tomat : Gula putih $50 \mathrm{~g}, \mathrm{~K} 3=100 \mathrm{~g}$ Tomat : Gula putih 30 $\mathrm{g}, \mathrm{K} 4=100 \mathrm{~g}$ Tomat : Gula putih $20 \mathrm{~g}, \mathrm{~K} 5=100 \mathrm{~g}$ Tomat : Gula merah $30 \mathrm{~g}, \mathrm{~K} 6=100 \mathrm{~g}$ Tomat : Gula merah $20 \mathrm{~g}, \mathrm{~K} 7=100 \mathrm{~g}$ Tomat : Gula putih $30 \mathrm{gr}+$ Gula merah $5 \mathrm{~g}$, dan K8 $=100 \mathrm{~g}$ Tomat : Gula merah $30 \mathrm{~g}+$ Gula putih $5 \mathrm{~g}$.

Kurto dengan delapan perlakuan tersebut untuk lebih jelasnya bisa dilihat pada Gambar 1

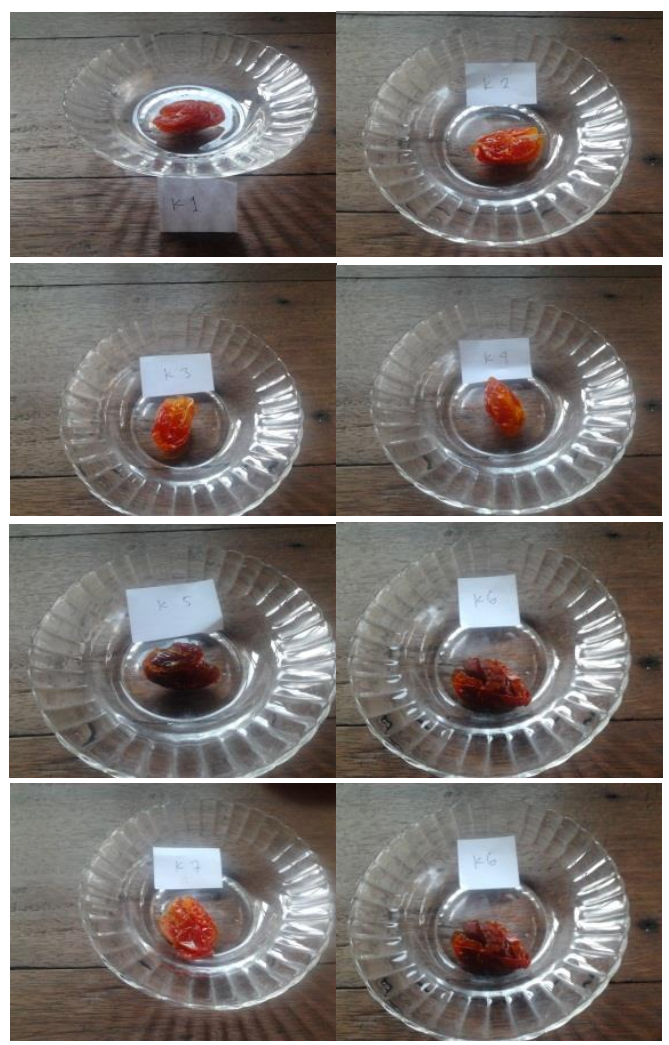

Gambar 1. Kurto Delapan Perlakuan 
Berdasarkan delapan sampel yang dibuat dilakukan uji organoleptik dan menghasilkan perlakuan yang paling banyak disukai oleh para panelis dari segi warna, aroma, rasa, tekstur yaitu K8 = $100 \mathrm{~g}$ Tomat : Gula merah $30 \mathrm{~g}+$ Gula putih $5 \mathrm{~g}$, dikarenakan pada uji anova hasilnya berpengaruh sangat nyata, dilanjutka dengan uji duncan hasilnya berdeda nyata. Penambahan gula merah sebanyak $30 \mathrm{~g}$ menyebabkan warna dari tomat berubah menjadi coklat tua dan penambahan gula pasir $5 \mathrm{~g}$ menambah rasa manis dari $\mathrm{K} 8$.

\section{Uji Organoleptik}

Hasil Uji Organoleptik disajikan pada Gambar 2 dan 3.

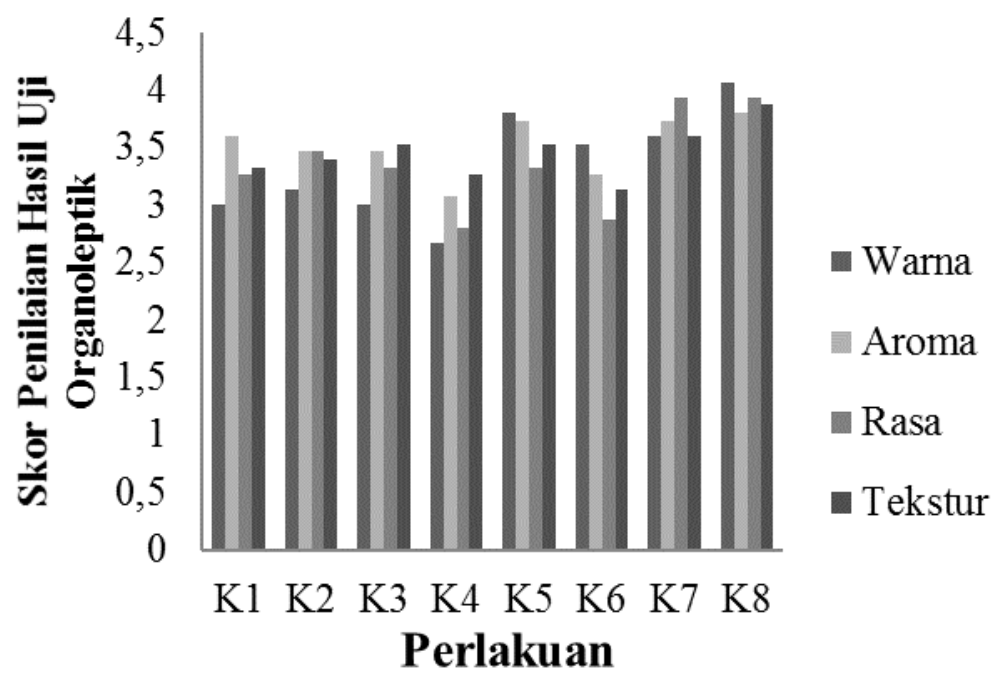

Gambar 2. Hasil Uji Hedonik Pada Optimasi Penambahan Gula

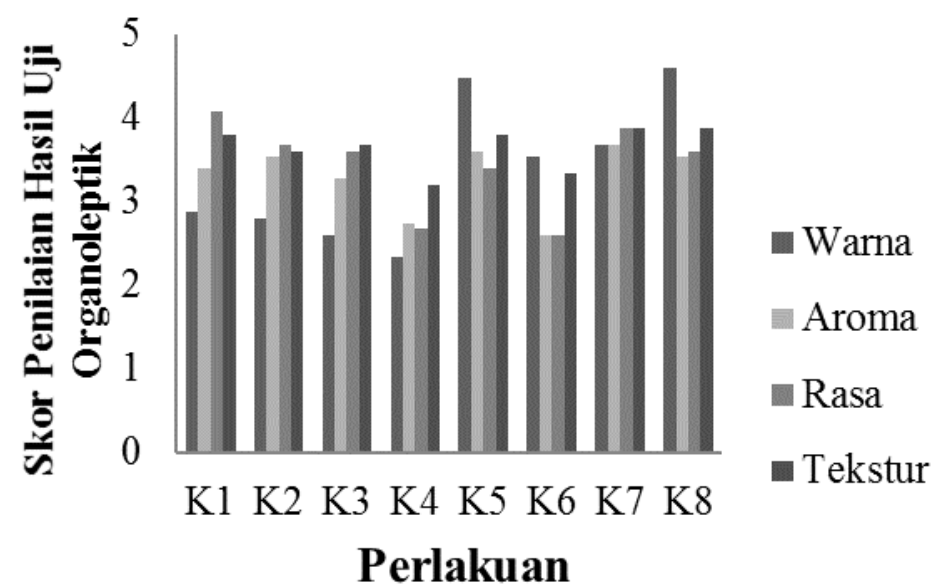

Gambar 3. Hasil Uji Mutu Hedonik Pada Optimasi Penambahan Gula

\section{Parameter Uji \\ Warna}

Berdasarkan uji Anova didapatkan kesimpulan bahwa perlakuan penambahan gula merah 30 $\mathrm{g}+5 \mathrm{~g}$ gula pasir pada optimasi penambahan gula pasir dan gula merah untuk uji hedonik dan mutu hedonik berpengaruh sangat nyata. Berdasarkan uji lanjutan DMRT (DuncanMultiple Range Test) taraf 5\% dan1\% untuk uji hedonik perlakuan K8 berbeda nyata dibandingkan dengan ke tujuh perlakuan lainnya, dan untuk uji mutu hedonik perlakuan K8 5\% berbeda nyata dibandingkan 
dengan perlakuan $\mathrm{K} 7, \mathrm{~K} 6, \mathrm{~K} 1, \mathrm{~K} 2, \mathrm{~K} 3, \mathrm{~K} 4$, dan untuk $1 \%$ berbeda nyata dibandingkan dengan perlakuan K7, K6, K1, K2, K3, K4.

\section{Aroma}

Berdasarkan uji Anova didapatkan kesimpulan bahwa perlakuan K8 dan K7 optimasi penambahan gula pasir dan gula merah untuk uji hedonik dan mutu hedonik berpengaruh sangat nyata. Berdasarkan uji lanjutan DMRT (DuncanMultiple Range Test) untuk uji hedonik taraf 5\% perlakuan $\mathrm{K} 8$ berbeda nyata dibandingkan dengan perlakun K3, K2, K6, K4 dan1\% perlakuan K8 berbeda nyata dibandingkan dengan perlakuan K6 dan K4, sedangkan untuk mutu hedonik perlakuan $\mathrm{K} 7$ taraf 5\% berbeda nyata dibandingkan dengan perlakuan $\mathrm{K} 6$ dan $\mathrm{K} 4$, dan1\% perlakuan K8 berbeda nyata dibandingkan dengan perlakuan K6 dan K4.

Rasa

Berdasarkan hasil uji hedonik rasa terhadap kurto (kurma tomat) di dapatkan nilai rata-rata tertinggi pada $\mathrm{K} 8$ dan $\mathrm{K} 7$ yaitu 3,93, sedangkan uji mutu hedonik didapatkan nilai rata-rata tertinggi pada K1 4,07. Hal ini disebabkan karena penambahan gula yang banyak akan menyebabkan rasa dari kurto akan menjadi sangat manis. Hal ini sesuai degan literatur yang menyebutkan bahwa manisan buah tomat kering yang baik adalah yang memiliki rasa manis (Zacky, 2015) . Berdasarkan uji Anova didapatkan kesimpulan bahwa perlakuan K8 dan K7 optimasi penambahan gula pasir dan gula merah untuk uji hedonik dan perlakuan K1 optimasi penambahan gula pasir untuk mutu hedonik berpengaruh sangat nyata. Berdasarkan uji lanjutan DMRT (DuncanMultiple Range Test) untuk uji hedonik taraf 5\% perlakuan K8 dan K7 berbeda nyata dibandingkan dengan perlakuan $\mathrm{K} 2, \mathrm{~K} 5, \mathrm{~K} 3, \mathrm{~K} 1, \mathrm{~K} 6, \mathrm{~K} 4$ dan1\% perlakuan $\mathrm{K} 8$ dan $\mathrm{K} 7$ berbeda nyata dibandingkan dengan perlakuan $\mathrm{K} 5, \mathrm{~K} 3, \mathrm{~K} 1, \mathrm{~K} 6, \mathrm{~K} 4$, sedangkan untuk mutu hedonik perlakuan $\mathrm{K} 1$ taraf $5 \%$ berbeda nyata dibandingkan dengan perlakuan $\mathrm{K} 2, \mathrm{~K} 8, \mathrm{~K} 3, \mathrm{~K} 5$, $\mathrm{K} 4, \mathrm{~K} 6$, dan1\% perlakuan K8 berbeda nyata dibandingkan dengan perlakuan K5, K4, K6.

\section{Tekstur}

Berdasarkan uji Anova didapatkan kesimpulan bahwa perlakuan K8 dan K7 optimasi penambahan gula pasir dan gula merah untuk uji hedonik dan mutu hedonik berpengaruh nyata dan berpengaruh sangat nyata. Berdasarkan uji lanjutan DMRT (DuncanMultiple Range Test) untuk uji hedonik taraf 5\% perlakuan $\mathrm{K} 8$ berbeda nyata dibandingkan dengan perlakun $\mathrm{K} 2, \mathrm{~K} 1, \mathrm{~K} 4, \mathrm{~K} 6$, dan $1 \%$ perlakuan $\mathrm{K} 8$ berbeda nyata dibandingkan dengan perlakuan $\mathrm{K} 1, \mathrm{~K} 4, \mathrm{~K} 6$, sedangkan untuk mutu hedonik perlakuan K8 dan K7 taraf 5\% berbeda nyata dibandingkan dengan perlakuan K6, $\mathrm{K} 4$, dan $1 \%$ perlakuan $\mathrm{K} 8$ dan $\mathrm{K} 7$ berbeda nyata dibandingkan dengan perlakuan K6, K4.

\section{Uji Kadar Air}

Hasil Uji Kadar Air disajikan pada Gambar 4.

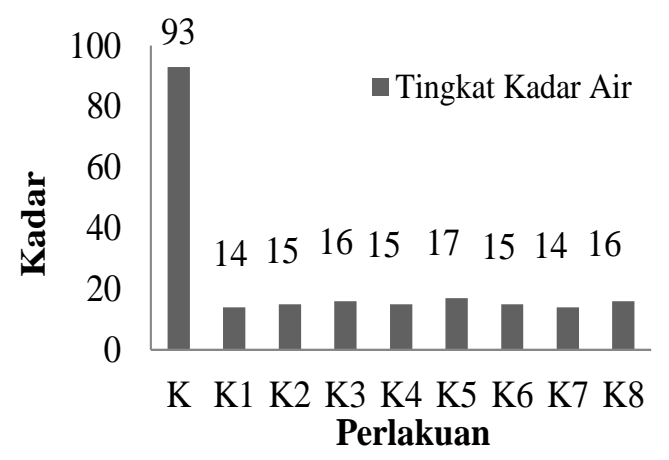

Gambar 4. Hasil Uji Kadar Air 
Berdasarkan uji kadar air yang dilakukan terhadap tomat dan kedelapan sampel kurto didapatlah hasil kadar air untuk sampel K (Tomat) yaitu 93\%, untuk sampel kurto yang memiliki hasil kadar air terendah perlakuan K1 dan K7 yaitu 14\%, sedangkan untuk hasil kadar air tertinggi diperoleh perlakuan K5 yaitu 17\%. Standarisasi kadar air untuk manisan kering berkisar 20-25\% (Hamzah \& Sribudianto, 2010).

\section{Uji Vitamin C}

Hasil Uji Kandungan vitamin disajikan pada Gambar dan 5.

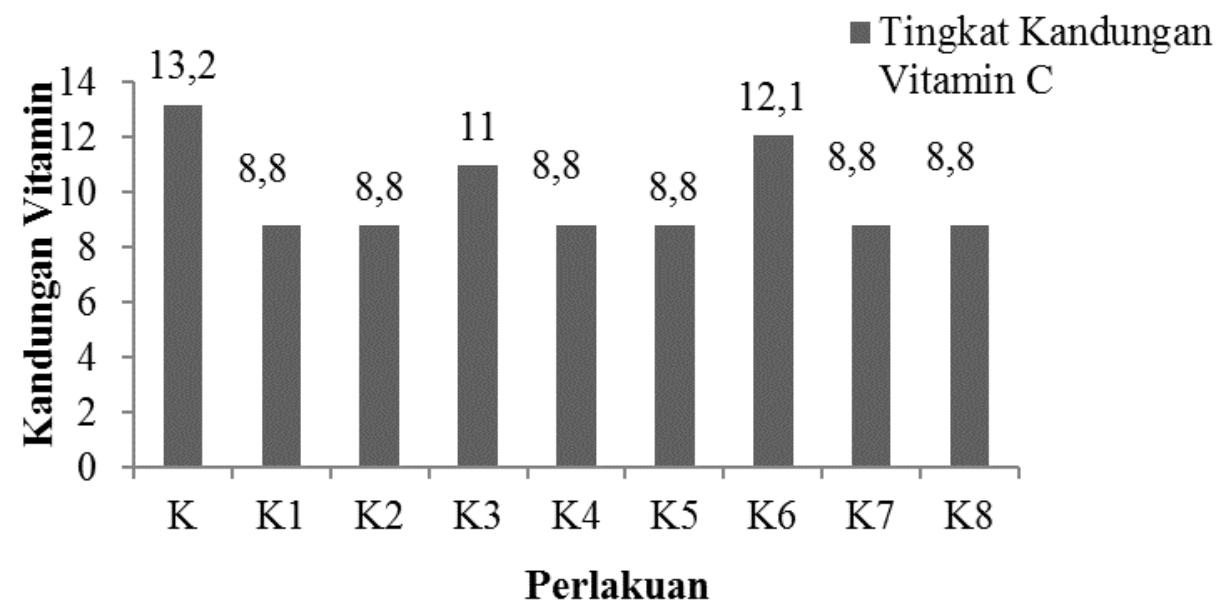

Gambar 5. Hasil Uji Kandungan Vitamin C

Berdasarkan hasil uji vitamin C yang dilakukan terhadap $100 \mathrm{~g}$ tomat dan $100 \mathrm{~g}$ kedelapan sampel kurto didapatlah hasil untuk sampel $\mathrm{K}$ (Tomat) yaitu 13,2 mg, untuk sampel kurto yang memiliki kandungan vitamin $\mathrm{C}$ terendah perlakuan $\mathrm{K} 1, \mathrm{~K} 2, \mathrm{~K} 4, \mathrm{~K} 5, \mathrm{~K} 7, \mathrm{~K} 8$ yaitu 8,8 mg, sedangkan yang memiliki kandungan vitamin $\mathrm{C}$ tertinggi diperoleh perlakuan $\mathrm{K} 6$ yaitu 12,1 mg. Setelah dijadikan kurto kadar vitamin $\mathrm{C}$ turun, penurunan tersebut desebabkan karena adanya pemanasan yang menyebabkan kerusakan vitamin C. Fungsi Vitamin C meningkatkan sel-sel darah putih yang dapat melawan infeksi sehingga flu sembuh lebih cepat, membantu mengaktifkan asam folat, meningkatkan penyerapan zat besi sehingga mencegah anemia, meregenerasi vitamin E sehingga bisa dipakai lagi sebagai anti-oksidan. Vitamin $\mathrm{C}$ ada yang alami juga ada yang sintetik (Aina dan Suprayogi, 2012).

\section{PENUTUP}

\section{Kesimpulan}

Berdasarkan hasil penelitian pembuatan kurto (kurma tomat) dengan optimasi penambahan gula pasir dan gula merah dapat disimpulkan bahwa :

1. Pembuatan kurto (kurma tomat) dengan penambahan gula pasir dan gula merah menggunakan delapan perlakuan, yaitu K1 = $100 \mathrm{~g}$ Tomat : Gula putih $100 \mathrm{~g}, \mathrm{~K} 2=100 \mathrm{~g}$ Tomat : Gula putih $50 \mathrm{~g}, \mathrm{~K} 3=100 \mathrm{~g}$ Tomat : Gula putih $30 \mathrm{~g}, \mathrm{~K} 4=100 \mathrm{~g}$ Tomat : Gula putih $20 \mathrm{~g}, \mathrm{~K} 5=100 \mathrm{~g}$ Tomat : Gula merah $30 \mathrm{~g}, \mathrm{~K} 6=100 \mathrm{~g}$ Tomat : Gula merah $20 \mathrm{~g}, \mathrm{~K} 7=100 \mathrm{~g}$ Tomat : Gula putih $30 \mathrm{gr}+$ Gula merah $5 \mathrm{~g}$, dan $\mathrm{K} 8=100 \mathrm{~g}$ Tomat : Gula merah $30 \mathrm{~g}+$ Gula putih $5 \mathrm{~g}$, pembuatan 
dilakukan dengan cara perendaman dengan air kapur \pm 2 jam, perebusan \pm 20 menit, pencampuran bahan, dan penjemuran \pm 2 hari.

2. Berdasarkan uji organoleptik yang telah dilakukan formulasi yang paling disukai para panelis yaitu perlakuan $\mathrm{K} 8=$ tomat $100 \mathrm{~g}$ : gula merah $30 \mathrm{~g}+$ gula pasir $5 \mathrm{~g}$.

3. Kandungan kadar air yang terendah yaitu $14 \%$ terdapat pada perlakuan K1 dan K7, sedangkan kandungan vitamin $\mathrm{C}$ yang paling tinggi yaitu $12,1 \mathrm{mg}$ terdapat pada perlakuan $\mathrm{K} 6$.

\section{DAFTAR PUSTAKA}

Aina, M., \& Suprayogi, D. (2012). Uji Kualitatif Vitamin C Pada Berbagai Makanan Dan Pengaruhnya terhadap Pemanasan.

Badan Pusat Statistik Kabupaten Tanah Laut. (2010). Tanah Laut Dalam Angka.

Hamzah, F., \& Sribudianto, E. (2010). Mutu Manisan Kering Buah Naga Merah (Hylocereus polyrhizus). Laboratorium Pengolahan Hasil Petanian Fakultas Pertanian Universitas Riau.

Hasanah, U. N. (2010). Proses Produksi Manisan Carika. Fakultas Pertanian Universitas Sebelas Maret Surakarta.

Zacky, A. (2015, Juli 29). Pembuatan Torakur. Dipetik Agustus 2, 2016, dari https://achmadzacky86.wordpress.com/ 